\title{
O USO DAS USINAS HIDRELÉTRICAS COMO UMA ENERGIA RENOVÁVEL
}

\author{
Pedro Henrique Freitas Tessarolo (FECILCAM, Brasil) pedro_13_freitas@hotmail.com \\ Artur Eugenio Grego Nuss (FECILCAM, Brasil) arturgnuss@hotmail.com \\ Guilherme de Almeida Tabachini (FECILCAM, Brasil) guilhermetabachini@hotmail.com \\ Pedro Henrique Barros Negrão (FECILCAM, Brasil) peter_b_negrao@hotmail.com
}

\begin{abstract}
Resumo: Esta tese tem o objetivo de demonstrar os elementos que constituem a forma de energia renovável utilizadas por uma usina hidrelétrica. De forma a demonstrar como pode atuar sobre o meio ambiente, destacando os pontos de vista positivos e negativos, as implantações e as decorrentes tem como objetivo deixar claro as vantagens e desvantagens desta forma eficiente e renovável de se produzir energia. Assim verificando a utilização das usinas hidrelétricas de forma não degradante ao meio ambiente. Os procedimentos metodológicos usados foram pesquisa bibliográfica e documental.
\end{abstract}

Palavras-chave: Energia. Hidrelétrica. Renovável. Usina.

\section{Introdução}

Usina hidrelétrica é um complexo arquitetônico, um conjunto de obras e de equipamentos, que tem por finalidade produzir energia elétrica por meio do aproveitamento do potencial hidráulico existente em um rio (CLEMENTE, 2001).

Frequentemente constroem-se represas que reprimem o curso da água, fazendo com que ela se acumule em um reservatório denominado barragem. A eficiência energética das hidrelétricas é muito alta, em torno de 90\%. O investimento inicial e os custos de manutenção são elevados, porém, o custo do combustível (água) é nulo. Por outro lado as usinas têm um impacto ambiental negativo e preocupante, tais como, perda da área de terra e biodiversidade, alteração do microclima, alteração da fauna e flora (muitas vezes extinguindo algumas espécies de animais). E inclusive o desenvolvimento de espécies nocivas à saúde humana, tais como, parasitas e transmissores de doenças endêmicas.

\section{Breve contexto histórico do Setor Elé- trico Brasileiro com ênfase na hidro- eletricidade}

O aparecimento das primeiras centrais geradoras de energia elétrica no Brasil ocorreu entre 1880 e 1900, a fim de atender às necessidades dos serviços públicos de iluminação e de atividades econômicas, como mineração, beneficiamento de produtos 
agrícolas, indústria têxtil e serrarias. Neste período, a capacidade instalada no Brasil multiplicou-se por 178 (cento e setenta e oito) vezes, passando de $61 \mathrm{~kW}$ para $10.850 \mathrm{~kW}$, dos quais $53 \%$ correspondiam a pequenas centrais hidrelétricas (GOMES et al., 2002).

No ano de 1900, o Brasil possuía uma população de 17 milhões de habitantes, que saltou para 30 milhões em 1920, aumentando significativamente o consumo interno e a necessidade de ampliação do parque industrial (GOMES et al., 2002).

Segundo Andrade (2006, p.21), durante a década de 1920, "a capacidade geradora instalada foi duplicada, sendo que, em 1920, dos 475,7 MW instalados, cerca de 77,8\% (setenta e sete ponto oito por cento) já eram de origem hídrica.

O crescimento acelerado da demanda e da oferta de energia continuou até 1940, porém em taxas menores que o da década anterior. Nesta época, a geração era voltada a sistemas isolados, sendo que a maioria dos empreendimentos consistia em pequenas centrais hidrelétricas. Durante esse período, o setor elétrico era dominado por empresas privadas de origem estrangeira (CLEMENTE, 2001).

Na década de 50, o Brasil enfrentou um grande déficit de energia elétrica, o que acarretou em constantes racionamentos em todo o país (GUIMARÃES, 2001). Em 1961, o Governo Federal criou a Eletrobrás (Centrais Elétricas Brasileiras S.A.) para a coordenação de todo o sistema elétrico nacional, funcionando também como banco de investimento do setor, além de holding do Governo Federal. A Eletrobrás e suas subsidiárias controlavam de forma verticalizada toda a cadeia do setor: Geração, Transmissão e Distribuição (CLEMENTE, 2001).

Clemente (2001) e Guimarães (2001) destacam que, aliado a este aumento, contribuíram para a crise os crescentes impasses entre o governo e as concessionárias privadas de energia em relação à política tarifária. $\mathrm{O}$ não entendimento entre as partes inibiu os investimentos. Além disso, o Brasil enfrentou uma grave estiagem entre os anos de 1952 a 1955, que afetou a oferta de energia hidrelétrica.

Foi neste momento de crise energética que o Brasil efetuou a transição do setor elétrico do modelo privado para o modelo público, seguindo a tendência mundial de estatização (CLEMENTE, 2001).

O primeiro passo desse processo foi dado com a criação da Companhia Hidrelétrica do São Francisco (CHESF), uma sociedade de economia mista ligada ao Ministério da Agricultura, responsável pela construção da primeira grande usina do Nordeste denominada atualmente de Paulo Afonso I, inaugurada em 1955. A partir deste momento, novas empresas foram criadas adotando o mesmo modelo que a CHESF, entre as quais podemos destacar a Centrais Elétricas de Minas Gerais (CEMIG), Companhia Hidrelétrica do Rio Pardo (CERP) - posteriormente absorvida pelas Centrais Elétricas de São Paulo (CESP), a Companhia de Energia Elétrica do Paraná (COPEL) (GUIMARÃES, 2001). 
Em 1961, o Governo Federal criou a Eletrobrás (Centrais Elétricas Brasileiras S.A.) para a coordenação de todo o sistema elétrico nacional, funcionando também como banco de investimento do setor, além de holding do Governo Federal. A Eletrobrás e suas subsidiárias controlavam de forma verticalizada toda a cadeia do setor: Geração, Transmissão e Distribuição (CLEMENTE, 2001).

Assim, o setor elétrico ficou sob a gerência do Estado que adotou uma política de expansão baseada em aproveitamentos de grande porte com ampla escala de produção centralizada e longos períodos de amortização de empreendimentos (POLIZEL, 2007).

No final da década de 70 , a trajetória de crescimento equilibrado e autossustentado começou a ficar comprometida, a partir da utilização do setor em políticas para captação de recursos externos e para controle do processo inflacionário por meio de forte contenção tarifária. Nesta fase, foram construídas grandes usinas, como Tucuruí e Sobradinho (GOMES et al., 2002).

Em meados da década de 80, inicia-se uma grave crise no setor, que continua até meados da década de 90. Clemente (2001) identifica como principais motivos desta crise:

- A incapacidade financeira de realizar investimentos necessários;

- O controle tarifário como fator de controle inflacionário;

- A elevação da inadimplência;

- O aumento das perdas técnicas e comerciais;
- A concorrência entre as concessionárias federais e estaduais por novas concessões de hidrelétricas e linhas de transmissão;

- A degradação da gestão técnica e administrativa das empresas;

- O aumento da demanda de energia decorrente do aquecimento da economia na época do plano real.

A incapacidade financeira de realizar investimentos necessários; o controle tarifário como fator de controle inflacionário; a elevação da inadimplência; o aumento das perdas técnicas e comerciais; a concorrência entre as concessionárias federais e estaduais por novas concessões de hidrelétricas e linhas de transmissão; a degradação da gestão técnica e administrativa das empresas; o aumento da demanda de energia decorrente do aquecimento da economia na época do plano real.

Nesta época, o setor energético nacional apresentava grandes dúvidas quanto ao rumo a seguir após anos de crise. A inexistência de regras e mecanismos estabelecidos que atraíssem investimentos privados para o atendimento da crescente demanda da população por energia elétrica contribuía para a continuidade do problema (CLEMENTE, 2001).

\section{Fundamentação Teórica}

A hidroeletricidade se constitui na obtenção de energia elétrica a partir do aproveitamento do potencial hidráulico de um determinado trecho 
de um rio, por meio da construção de uma barragem e pela consequente formação de um reservatório (BERMANN, 2007).

Atualmente, as usinas hidrelétricas são responsáveis por aproximadamente $18 \%$ da produção de energia elétrica no mundo. Esses dados só não são maiores pelo fato de poucos países apresentarem as condições naturais para a instalação de usinas hidrelétricas.

A construção das usinas hidrelétricas se dá sempre em locais onde podem ser aproveitados os desníveis naturais dos cursos dos rios e deve-se ter uma vazão mínima para garantir a produtividade. A transformação da energia potencial das águas dos rios em energia elétrica, aproveitando as grandes corredeiras e quedas d'água são uma das fontes mais econômicas de se produzir eletricidade.

Um rio não é percorrido pela mesma quantidade de água durante o ano inteiro. Em uma estação chuvosa, é claro, a quantidade de água aumenta. Para aproveitar ao máximo as possibilidades de fornecimento de energia de um rio, deve-se regularizar-se a sua vazão, a fim de que a usina possa funcionar continuamente com toda a potência instalada.

A vazão de água é regularizada pela construção de lagos artificial. Uma represa, construída de material muito resistente - pedra, terra, frequentemente cimento armado, fecha o vale pelo qual corre o rio. As águas param e formam o lago artificial. Dele pode-se tirar água quando o rio está baixo ou mesmo seco, obtendo-se assim uma vazão constante.

Contudo, nem todas as partes do mundo são adequadas para a produção de energia dessa forma. Para produzir energia dessa maneira, uma região precisa de montanhas e de rios e córregos de escoamento rápido, ou de precipitações pesadas.

A energia elétrica é gerada pela força da água em movimento é conhecida como energia potencial, essa água passa por tubulações da usina com muita força e velocidade, realizando a movimentação das turbinas. Nesse processo, ocorre a transformação de energia potencial (energia da água) em energia mecânica (movimento das turbinas).

As turbinas em movimento estão conectadas a um gerador, que é responsável pela transformação da energia mecânica em energia elétrica. Toda energia elétrica gerada dessa maneira é levada por cabos, dos terminais do gerador até à rede de distribuição. O Brasil destaca-se mundialmente nessa categoria, possuindo a maior usina do mundo em capacidade de geração de eletricidade que é a Usina de Itaipu, situada no rio Paraná, na divisa do Brasil com o Paraguai.

A energia que pode ser fornecida por unidade de tempo chama-se potência, e é medida em watt (W). Esta pode ser calculada multiplicando-se a tensão em volts que ela é capaz de fornecer pela corrente em ampères que distribui.

Uma linha de transmissão, portanto, é capaz de transportar a mesma potência de duas maneiras: com voltagem elevada e corrente de baixa intensidade, ou com voltagem baixa e alta corrente.

Quando a energia elétrica atravessa um condutor, transforma-se parcialmente em calor. 
Essa perda é tanto maior quanto mais elevada for a intensidade da corrente transportada e maior for a resistência do fio condutor. Assim, seria conveniente efetuar a transmissão da energia elétrica por meio de fios muito grossos, que apresentam menos resistência. Porém, não se pode aumentar excessivamente o diâmetro do condutor, pois isso traria graves problemas de construção e transporte, além de encarecer muito a instalação.

A energia elétrica é, pois, produzida a uma tensão relativamente baixa, que em seguida é elevada, para fins de transporte. Ao chegar às vizinhanças dos locais de utilização, a tensão é rebaixada. Essas elevações e abaixamentos são feitos por meio de transformadores.

\section{Fatores que afetam benefícios de uma central hidrelétrica}

O benefício de uma Pequena Central Hidroelétrica - PCH - é a venda de energia que gera receitas ao empreendedor. Além da renda proporcionada pela comercialização de energia, a viabilidade econômica de um empreendimento dependerá também das despesas com juros e amortização do capital investido, dos custos de operação e manutenção, além de encargos administrativos (SCHEREIBER, 1977).

A energia primária que se processa em uma central hidrelétrica é a energia potencial gravitacional acumulada devido a uma diferença de altitude no curso do rio. Esta se transforma em energia cinética de rotação, através da ação da turbina. E assim, a energia cinética é convertida para mecânica e, consequentemente, transforma-se em energia elétrica através do gerador acoplado na turbina (CRUZ, 2008):

\section{Epotencial $\rightarrow$ Ecinética $\rightarrow$ Emecânica $\rightarrow$ Eelétrica}

Um determinado volume d'água caindo de uma certa altura produz o trabalho teórico de (SCHEREIBER, 1977) (Equação 1):

$$
T=\gamma^{*} V * H(e m t . m)
$$

Onde, $\mathrm{T}=$ trabalho teórico; $\gamma=$ peso específico da água, $1 \mathrm{t} / \mathrm{m}^{3} ; \mathrm{V}$ = volume d'água, em $\mathrm{m}^{3} ; \mathrm{H}$ = altura da queda bruta.

A potência teórica de um aproveitamento hidrelétrico é definida por (Equação 2):

$$
P t=Q * H(e m t . m / s)
$$

Onde, $\mathrm{Q}$ é igual à descarga, m³/s. A potência hidrelétrica é a energia que se fornece em um determinado intervalo de tempo e a unidade é em watt (W), ou seja, J/s.

Geralmente para centrais hidrelétricas utilizam-se as unidades kW12, MW ou GW. Todavia, a transformação de energia potencial em cinética e posteriormente para mecânica e elétrica acarreta em perdas, pois estas conversões não são totalmente eficientes. Sendo que $\eta$ é o fator de rendimento da turbina e do gerador e $\mathrm{Hl}_{\mathrm{iq}}$ é a queda líquida, que é a queda bruta menos as perdas de carga nos órgãos de adução, tem-se que a potência efetiva corresponde a Equação 3. 


$$
P e f=9,81 * \eta * Q * H l_{i q}(e m k W)
$$

Assim, a produção de energia elétrica utilizando a energia mecânica da água é um produto da queda líquida, das vazões disponíveis e do rendimento do conjunto turbina gerador multiplicada pelo tempo (USACE, 1985).

Usualmente, as PCH são projetadas a fio d'água, sem reservatório ou com pequeno reservatório, capaz somente de compensação diária ou semanal da descarga, aproveitando, assim, apenas a água que flui no regime natural do rio, variável durante o ano e no decorrer dos anos. Neste sentido, os estudos de concepção de uma usina hidrelétrica devem avaliar durante quanto tempo certa descarga estará provavelmente disponível ou ultrapassada, e concomitantemente a queda correspondente e a potência resultante destes fatores (SCHEREIBER, 1977).

Uma das relações que traduzem a ideia apresentada no parágrafo anterior e frequentemente utilizada na análise de empreendimentos é o fator de capacidade de um aproveitamento. $\mathrm{O}$ fator de capacidade de uma pequena usina hidrelétrica é uma medida da disponibilidade de vazões no local do empreendimento e de quão eficiente é sua utilização para produção de energia (CETC, 2004). Ele consiste na relação da energia média produzida em determinado tempo pela capacidade máxima de geração neste período, conforme Equação 4:
Onde: Pot é a potência instalada (MW); Fc é o fator de capacidade; EFe é energia média produzida em MW médios.

A estimativa da energia produzida, assim como a definição da potência instalada de um aproveitamento, é resultante de estudos complexos interdisciplinares que envolvem avaliação da disponibilidade hídrica e das restrições socioambientais, a definição do arranjo e das perdas hidráulicas, o estudo da variação dos níveis de montante e de jusante, análises de custo-benefício, entre outros estudos que são elaborados com maior ou menor complexidade em função da fase de projeto.

Um aspecto que afeta diretamente o benefício de usinas em derivação e que merece destaque devido à sua estreita relação com o meio ambiente é a chamada vazão sanitária, remanescente ou ecológica.

Segundo Garcia e Andreazza (2004, p.2), "a "vazão ecológica" é aquela que possibilite ao ambiente hídrico manter a integridade dos processos naturais que se dão entre o meio físico e a biota, valorizando especialmente as inter-relações vinculadas às variações do regime hidrológico natural".

Neste sentido, o estabelecimento de vazões mínimas à jusante das barragens implica na não contabilização destas descargas para produção de energia, fato que não pode ser esquecido na avaliação do benefício gerado por um aproveitamento. 
Dentro deste contexto, a metodologia de prospecção proposta neste trabalho objetiva discutir e apresentar, entre outros aspectos, uma alternativa para a avaliação da energia que pode ser produzida e da potência instalada para determinado local, de forma expedita e preliminar, utilizando, fundamentalmente, dados secundários.

\section{Vantagens}

Podem se adequar como vantagem os seguintes quesitos: fonte de energia renovável e confiável; longa vida útil; o "combustível" (a água), apesar de já estar sendo cobrado, possui custo muito baixo; pode contribuir positivamente para os chamados usos múltiplos - abastecimento de água, navegabilidade, irrigação, turismo, lazer, pesca e outros projetos regionais de desenvolvimento; o custo final da energia, com custos de operação e manutenção (O\&M), ainda é atrativo, mesmo com os custos ambientais e sociais internalizados.

\section{Impacto Ambiental Positivo}

Os principais impactos considerados positivos, são a regularização de vazão e o armazenamento de energia potencial, ambos em maior ou menor grau de acordo com a capacidade do reservatório associado.

Expulsão de populações e perda do equilíbrio socioeconômico local, principalmente devido a estratégias e projetos de reassentamento inadequados e aos fluxos migratórios de trabalhadores para o local; reação social e de ambientalis- tas - Movimento dos Atingidos pelas Barragens (MAB), ONGs ambientalistas etc.; necessidade de grandes volumes de capital; retorno do investimento em longo prazo; extenso cronograma de implantação; a obtenção de financiamentos, devido aos impactos ambientais negativos, está cada vez mais complexa e com taxas mais elevadas; dependendo da área do reservatório e das condições climáticas, pode apresentar grande perda por evaporação; ao longo de vários anos, os reservatórios, em geral, apresentam perda de volume devido à deposição de sedimentos trazidos pelo fluxo do rio.

A análise final ponderada da totalidade dos critérios aponta para que os dois seja uma classe $\mathrm{A}$, isto é $50 \%$ melhor que a prática de referência. Para Galão (2013), os dois hotéis têm potencial de progressão para a classe seguinte (classe $\mathrm{A}+$ ), caso implementem certas medidas de melhoria. O hotel Marina Palace apresenta, a nível internacional e brasileiro, muito boas práticas nas áreas da energia e água, mas desempenhos fracos na área dos resíduos. No hotel Marina All Suites o comportamento é similar, exceto na área da água onde apresenta um desempenho muito reduzido (classe F) decorrente do modo de utilização.

\section{Impactos Ambientais Negativos}

Os impactos negativos por sua vez, se traduzem na perda de área de terra e de biodiversidade; alteração do microclima; alteração da fauna e da flora, inclusive desenvolvimento de espécies nocivas à saúde humana, como parasita e transmissores de doenças endêmicas; per- 
turbação da ictiofauna e de ecossistemas aquáticos; alterações no regime e na qualidade da água; risco de rompimento de barragens; em reservatórios que não se tenha removido corretamente a cobertura vegetal do fundo, previamente ao enchimento, emissão de gás metano (CH4), um dos gases de efeito estufa (GEE).

\section{Os conflitos socioambientais na imple-} mentação das usinas hidrelétricas

Com relação aos conflitos socioambientais, Little (2001, p. 107) os caracteriza como disputas entre grupos de atores sociais que possuem distintas formas de se relacionar e interagir com o meio natural. Dispondo que:

Cada ator social tem sua própria forma de adaptação, ideologia e modo de vida, que entram em choque com as formas dos outros grupos dando assim a dimensão social do conflito socioambiental.

Para este autor, os conflitos socioambientais podem ser classificados em três principais tipologias a depender se as disputas ocorrem em torno: $i$ ) do controle sobre os recursos naturais; ii) dos impactos ambientais e sociais gerados pela ação humana e natural e; iii) do uso dos conhecimentos ambientais.

Os conflitos podem ser caracterizados, ainda, pelos elementos: natureza, atores sociais, campo específico, objeto em disputa, lógica ou dinâmica de evolução, mediadores e tipologia (FARIA, 2004b).

Bredariol (2001), por sua vez, argumenta que os conflitos ambientais nas áreas urbanas dos países em desenvolvimento são atrelados à questão da equidade social. Já nas áreas rurais, eles estão relacionados à apropriação de recursos naturais ou à preservação de culturas.

Little (2001, p. 115) salienta ainda que:

Cada conflito tem seus ambientes naturais particulares, seus atores sociais e seus nós próprios de conflito (...) o tratamento, e possível resolução dos conflitos, precisam ser precedidos por uma etapa de pesquisa e análise das raízes e causas do mesmo.

O conflito pode nascer, ainda, de disputas entre as classes sociais detentoras do capital e aquelas detentoras da força de trabalho, devido a interesses divergentes quanto à apropriação de riquezas, quanto ao reconhecimento social e quanto à detenção de poder. Nesse caso, os diferentes grupos sociais se enfrentam nos campos econômicos, político e social (FARIA, 2004b).

Para Leff (2000), os conflitos ambientais são desencadeados por interesses divergentes quanto à utilização e apropriação dos recursos naturais e levam a sociedade a pensar de uma maneira mais voltada para o desenvolvimento sustentável. Esses conflitos não serão resolvidos pela ciência ou pela ecologia, mas sim pelas diferentes formas de enxergar o ambiente, pela diversidade cultural e pelo saber ambiental. A participação da sociedade é fundamental para a gestão ambiental, e o diálogo de saberes produzido pelas diferentes culturas e identidades auxiliará na resolução dos conflitos ambientais.

Dessa forma, pode-se afirmar que a consolidação do setor elétrico brasileiro depende de um Estado de interesse social e ambiental forte, capaz de promover os pilares necessários à sua expansão sem prescindir. Contudo, da criação 


\section{ReLAlnEP}

de instrumentos de mercado que diminuam as assimetrias de poder e de informações entre os atores envolvidos (FROTA, 2001).

Aos planejadores de políticas públicas cabe informar à sociedade que a disponibilização de energia elétrica na quantidade demandada implica impactos ambientais e, consequentemente, a potencialização dos conflitos deles decorrentes, os quais precisam ser "negociados, mitigados e acertados pelos agentes" (FROTA, 2001).

Moret e Ferreira (2008) argumentam que os conflitos no setor elétrico surgiram por causa da apropriação da cadeia de energia pelo poder econômico "transformando-a somente em benefícios econômicos com acumulação de capital".

Para Araújo et al. (2000), os conflitos socioambientais entre governo e a população atingida por barragens ocorre, principalmente, em decorrência de problemas que envolvem a avaliação incompleta dos processos de transferência de populações afetadas e das repercussões sociais peculiares às grandes obras. Assim, Araújo et al. (2000) concluem que essas avaliações, incompletas ou incompatíveis quanto aos custos e à duração do empreendimento, terminam por acirrar os conflitos.

Diante desse contexto, o mais importante a se considerar é a participação das populações atingidas no processo de decisão inerente à implantação de usinas hidrelétricas. Nessas situações, o princípio majoritário adotado como procedimento democrático não tem validade, uma vez que os efeitos da instalação desses empreendimentos atingem uma minoria. As- sim, "deve-se adotar a construção de consensos, reconhecendo interesses divergentes que devem ser incorporados no processo de negociação" (BERMANN, 2007).

\section{Considerações Finais}

De acordo com os dados citados acima, tendo como ponto de vista sustentável e renovável, o grande aumento da preocupação sobre energias limpas e menos degradantes para o meio ambiente, vimos que essa energia é parcialmente colaboradora com o requisitos sustentáveis e renováveis, pois, ao mesmo tempo que tem um grande aproveitamento no processo produtivo da energia, ela é consideravelmente degradante à natureza.

Para que os conflitos em políticas públicas contribuam para uma mudança social positiva, eles precisam ser bem geridos, e essa gestão depende muito da estrutura política do país, que limita ou facilita a implementação de políticas.

A melhor forma de se resolverem os conflitos socioambientais é mediante a criação de espaços públicos de participação que viabilizem a emancipação política da sociedade, possibilitando sua efetiva responsabilização para a gestão ambiental no setor elétrico.

\section{Referências}

AGÊNCIA NACIONAL DE ENERGIA ELÉTRICA (ANEEL). Banco de Informações de Geração: capacidade de geração do Brasil. Disponível em <http:/ / www.aneel.gov.br/aplicacoes/capacidade brasil/capacidadebrasil.asp $>$. Acesso em: 12 nov. 2012 
AGÊNCIA NACIONAL DE ENERGIA ELÉTRICA (ANEEL). Resolução Normativa ANEEL $\mathbf{n}^{\circ}$ 116, de 29 de novembro de 2004. Altera o Regimento Interno da ANEEL, aprovado pela Portaria MME $\mathrm{n}^{\circ}$ 349, de 28 de novembro de 1997, para modificar a estrutura administrativa da Agência Nacional de Energia Elétrica - ANEEL. Diário Oficial da União. Brasília, DF, 2004.

ANDRADE, J.S.O. Pequenas Centrais Hidrelétricas: Análise das causas que impedem a rápida expansão de um programa de PCH no Brasil. 2006. 88 p. Dissertação (Mestrado) - Programa de PósGraduação em Engenharia, Universidade de Salvador, Salvador, 2006. Disponível em: $<$ http://tede.unifacs.br/tde_busca/arquivo.php?co dArquivo=126>. Acesso em: 17 nov. 2012.

ARAÚJO, Maria Lia Corre a de; CALDAS NETO, Magda de; LIMA, Ana Eliza Vasconcelos (Org.). Sonhos submersos ou desenvolvimento?: impactos sociais da Barragem de Itaparica. Recife: Massangana, 2000.

BAGATTOLI, S.G. Gestão estratégica de energia elétrica e seus reflexos no desenvolvimento regional. 2005. 329 p. Dissertação (Mestrado) Centro de Ciências Humanas e da Comunicação, Universidade Regional de Blumenau, Blumenau, 2005.

BERMANN, Célio. Impasses e controvérsias da hidreletricidade. Revista Estudos Avançados, v. 21, n. 59, 2007.

BREDARIOL, Celso. Conflito ambiental e negociação para uma política local de meio ambiente. 2001. 244 f Tese (Doutorado em Planejamento Energético)-Universidade Federal do Rio de Janeiro, Rio de Janeiro, 2001.

BP GLOBAL British Petroleum. Disponível em: <htpp//: www.bp.com> Acesso em: 12 nov. 2012.

CACHAPUZ, Paulo Brandi de Barros (Org.). História da operação do sistema interligado nacional. Rio de Janeiro: Centro da Memória da Eletricidade no Brasil, 2003. 416 p.

CANMET ENERGY TECHNOLOGY CENTRE (CETC). Clean energy project analysis: RETScreen engineering \& cases textbook. Canadá. 2004. 51p.
CLEMENTE, L. Seleção de potência instalada ótima no de PCHs no contexto de mercados competitivos. 2001. 270 p. Dissertação (Mestrado) - Universidade Federal do Paraná, Curitiba, 2001. Disponível em: $<$ http://www.aneel.gov.br/biblioteca/trabalhos/t rabalhos/Dissertacao_Leonardo_Clem ente.pdf>. Acesso em: 12 nov. 2012.

CRUZ, T.B. Estimativas de potenciais hidrelétricos remanescentes com base em ferramentas de geoprocessamento. 2008. 54p. (Projeto final de graduação em engenharia hídrica). Universidade Federal de Itajubá, Itajubá, 2008.

FARIA, I. D. O descompasso e o piroscópio: uma análise dos conflitos socioambientais do projeto da Usina Hidrelétrica Belo Monte. 2004. 420 f. Tese (Doutorado)-Centro de Desenvolvimento Sustentável, Universidade de Brasília, Brasília, 2004b.

FROTA, I. O setor elétrico e seus conflitos: os novos e os velhos desafios. In: BURSZTYN, M. (Org.). A difícil sustentabilidade: política energética e conflitos ambientais. Rio de Janeiro: Garamond, 2001.

GOMES, A.C.S., ABARCA, C.D.G., FARIA, E.A.S.T., FERNANDES, H.H.O. BNDES, $\mathbf{5 0}$ anos: Histórias Setoriais - Setor Elétrico. Brasília: BNDES, 2002, 21 p. Disponível em: $<$ http://www.bndes.gov.br/conhecimento/livro_ setorial/setorial14.pdf $>$. Acesso em: 12 nov. 2012.

GUIMARÃES, G. Crise energética e privatização. Brasília: Consultoria Legislativa da Câmara dos Deputados, 2001, p. 11.

LIMA, F.A. A regulação por contratos no setor elétrico brasileiro: $O$ contrato de comercialização de energia elétrica no ambiente regulado CCEAR e os leilões de energia. 43 p. Monografia. ( Pós Graduação em Direito da Regulação e Defesa da Concorrência) - Instituto CEUB de Pesquisa e Desenvolvimento, Universidade de Brasília, Brasília, 2006.

LITTLE, P. E. Os conflitos socioambientais: um campo de estudo e de ação política. In: BURSZTYN, M. (Org.). A difícil sustentabilidade: política energética e conflitos ambientais. Rio de Janeiro: Garamond, 2001. 
MORET, A.S.; FERREIRA, I.A. UHEs do Madeira: o planejamento para atendimento da demanda elétrica, celeridade nos estudos e as conseqüências socioambientais. In: CONGRESSO BRASILEIRO DE ENERGIA, 12., 2008, Rio de Janeiro. Anais... Rio de Janeiro: COPPE, UFRJ, 2008.

POLIZEL, L.H. Metodologia de prospecção e avaliação de pré-viabilidade expedita de geração distribuída: caso eólico e hidráulico. 2007. 160p. Dissertação (Mestrado) - Escola Politécnica, Universidade de São Paulo, São Paulo, 2007.

SCHREIBER, G.P. Usinas Hidrelétricas. São Paulo, Edar Blucher; Rio de Janeiro,

ENGEVIX, 1977.

US ARMY CORPS OF ENGINEERS (USACE). Feasibility analysis in small hydropower planning. $1979 . \quad$ Disponível em http://140.133.76.129/publications/ engmanuals/. Acesso em: 06 dez. 2012. 